\title{
Comparative Analysis of Biochemical Compounds of Leaf, Flower and Fruit of Couroupita guianensis and Synthesis of Silver Nanoparticles
}

\author{
Prakash Pandurangan*, Madhumitha Sahadeven, Swetha Sunkar, Sai Krishna Nerella Mohana Dhana
}

Prakash Pandurangan*, Madhumitha sahadeven, Swetha Sunkar, Sai Krishna Nerella Mohana Dhana

Department of Biotechnology, sathyabama institute of science and technology, Chennai, Tamil Nadu, INDIA.

\section{Correspondence}

Prakash Pandurangan

Department of Biotechnology, sathyabama institute of science and technology, Chennai, Tamilnadu, INDIA.

Phone no: $91+9840522688$

E-mail: kpprakashmtech@gmail.com

\section{History}

- Submission Date: 18-9-2017

- Review completed: 27-10-2017;

- Accepted Date: 31-12-2017

DOI : 10.5530/pj.2018.2.55

Article Available online

http://www.phcogj.com/v10/i2

\section{Copyright}

(c) 2018 Phcog.Net. This is an openaccess article distributed under the terms of the Creative Commons Attribution 4.0 International license.

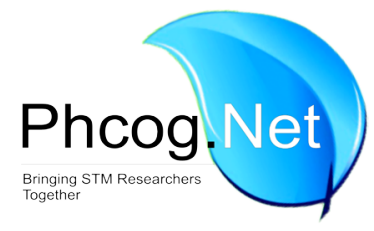

\begin{abstract}
Couroupita guianensis is commonly known as cannonball tree, belonging to the family Lecythidaceae. This tree has enormous medicinal values since most of its parts are used as medicines traditionally. In this work, two major aspects were studied. Firstly, the phytochemical screening and biological activities of various extracts of leaf, flower and fruit are prepared and studied. Secondly, silver nanoparticles were synthesized from these parts, characterized instrumentally and checked for its antibacterial activity. This study reveals that except the aqueous extracts, all other extracts have good antioxidant and antibacterial activity hence stating the presence of bioactive compounds. Flower mediated nanoparticles showed better results than others which may be due to the presence of certain phytochemical compounds responsible for the reduction and capping of silver nanoparticles. These results showed the potential of Couroupita guianensis and further investigation to isolate such pharmacologically active compounds that can be used in the production of novel drugs for various diseases would be promising.

Key words: Couroupita guianensis, Bioactive compounds, Nanoparticles.
\end{abstract}

\section{INTRODUCTION}

Plants are one of the most valuable sources of the natural products. Almost all the parts of the plants namely leaves, flowers, fruits, stem and root have their own bioactive compounds which can be used for therapeutic purposes. Typically medicinal plants ensure an extensive supply of antibiotic, antifungal, antiseptic, analgesic compounds etc. ${ }^{1}$ Recently, traditionally used medicinal plants have attracted the attention of scientific and pharmaceutical communities because of its effectiveness in managing multi-drug resistant bacterial strains and its negligible side effects. The World Health Organization (WHO) estimates that $80 \%$ of the population of south Asian and African countries prefers herbal medication. Couroupita guianensis is one such medicinal plant which is widely used in Chinese traditional medicine. Couroupita guianensis Aubl is a large deciduous tropical tree belonging to the family Lecythidaceae (Brazil nut family). It is commonly referred as "Cannonball tree" in English (because of the cannonball like fruit structure), "Kailashpati" in Hindi ${ }^{2}$ and "Mallikarjuna" in Telugu, "Nagalinga pushpam" in Tamil owing to its shivalingam shape at the centre of the flower and the snake hood like pollen structure. Despite its structural speciality, various part of this tree has been reported to contain oils, ketosteroids, glycosides, isatin, indurubin, couroupitine and phenolic substances with medicinal properties.

\section{MATERIALS AND METHODS}

\section{Collection of plant material}

Couroupita guianensis leaves, flowers and fruits were collected freshly from Krishnan koil, Nagercoil, Kanyakumari district. The samples were ensured to be free from diseases and washed for removal of dust particles. The samples are then shade dried and powdered. The nature of the powder is identified by depending on the characteristics such as the color, odor, taste and texture which can be examined physically.

\section{Preparation of extracts}

Various extracts were prepared for the samples using water, ethyl acetate and chloroform (1:4 ratios) by homogenization method individually. After $24 \mathrm{~h}$, the solution is filtered using Whatman no. 1 filter paper and the extracts were concentrated by evaporation. The crude extracts obtained are used for following tests and stored in sterile eppendorfs at $4^{\circ} \mathrm{C}$. The color and consistency of the extracts are observed.

\section{Phytochemical analysis}

The presence of bioactive compounds is identified individually in leaves, flowers and fruit extracts of Couroupita guianensis by using the standard procedures as described by ${ }^{3,4,5,6}$

Cite this article: Pandurangan P, Sahadeven M, Sunkar S, Dhana SKNM. Comparative Analysis of Biochemical Compounds of Leaf, Flower and Fruit of Couroupita guianensis and Synthesis of Silver Nanoparticles. Pharmacog J. 2018;10(2):315-23. 


\section{Test for Carbohydrates}

To $0.5 \mathrm{ml}$ of filtrate, $0.5 \mathrm{ml}$ of Benedict's reagent is added. The mixture is then heated on a boiling water bath for $2 \mathrm{~min}$. A characteristic colored precipitate indicates the presence of sugar.

\section{Test for Alkaloids}

To a few drops of plant sample extract, 2 drops of Mayer's reagent are added along the sides of test tube. Appearance of white creamy precipitate indicates the presence of alkaloids.

\section{Test for Amino acids}

To $2 \mathrm{ml}$ of aqueous filtrate, 2 drops of Ninhydrin solution is added. Appearance of purple color indicates the presence of amino acids.

\section{Test for Theo bromine}

The extract is dissolved in 2 test tubes with $1 \mathrm{ml}$ of hot water and $1 \mathrm{ml}$ of cold water each. If the extract dissolves in hot water and does not dissolve in cold water, it indicates the presence of Theo bromine.

\section{Test for Saponins}

The extract is diluted with distilled water and made up to $20 \mathrm{ml}$. The suspension is shaken for $15 \mathrm{~min}$. Formation of foam indicates the presence of Saponins.

\section{Test for Glycosides}

To $2 \mathrm{ml}$ of filtered hydrolysate, $3 \mathrm{ml}$ of chloroform is added, shaken and the chloroform layer is separated, and $10 \%$ ammonia solution is added to it. Pink color indicates presence of glycosides.

\section{Test for Phytosterols}

The extract is dissolved in $2 \mathrm{ml}$ of acetic anhydride. To this, 1 or 2 drops of concentrated sulfuric acid is added slowly along the sides of the test tube. An array of color change shows the presence of Phytosterols.

\section{Test for Flavonoids}

Extracts were treated with few drops of lead acetate solution. Formation of yellow color precipitate indicates the presence of flavonoids.

\section{Test for Tannins}

To a few drops of extract, $2 \mathrm{ml}$ of dilute ferric chloride solution (5\%) is added. Formation of violet color indicates the presence of tannins.

\section{Test for Terpenoids}

To a $2 \mathrm{ml}$ of extract, few drops of saturated solution of trichloro acetic acid are used. Formation of colored precipitate confirms the presence of terpenoids.

\section{Determination of antioxidant activity by DPPH-scavenging assay}

The free radical scavenging activity of the leaves, flowers and fruit extracts of Couroupita guianensis and of standard solution (ascorbic acid) was investigated using 1, 1-diphenyl-2-picrylhydrazyl (DPPH) radical scavenging method as reported in the literature ${ }^{7}$ using Ascorbic acid as standard.

Briefly, $0.1 \mathrm{mM}$ of ethanolic DPPH radical solution was prepared in ethanol and initial absorbance was measured at $517 \mathrm{~nm}$. An aliquot $(1.0 \mathrm{ml})$ of each sample (with appropriate dilution $100 \mu \mathrm{g} / \mathrm{ml}$ ) was added to 3.0 $\mathrm{ml}$ of ethanolic DPPH radical solution. Decrease in colour was measured after incubation in dark for $30 \mathrm{~min}$.

$$
\text { Scavenging activity }(\%)=\frac{(\text { AbsControl }- \text { Abssample })}{\text { AbsControl }} \times 100
$$

\section{Antibacterial activity of the extracts by agar well diffusion method}

The antibacterial activity of different extracts of leaves, flowers and fruits were evaluated against 3 bacteria which includes 2 g-negative bacteria (Pseudomonas aeuroginosa and Escherichia coli) and a g-positive bacteria (Bacillus subtilis) by agar well diffusion assay as described. ${ }^{8}$ The bacterial test organisms were grown in nutrient broth for $24 \mathrm{~h}$. One milliliter nutrient broth culture of each bacterial organism was used to prepare bacterial lawns on nutrient agar plates. The wells were cut and $100 \mu \mathrm{L}$ of extract was loaded and incubated at $37^{\circ} \mathrm{C}$. The plates were examined for evidence of zones of inhibition, which appear as a clear area around the wells.

\section{TLC analysis}

Thin-layer chromatography (TLC) is a chromatography technique used to separate non-volatile mixtures. Thin-layer chromatography is performed on a sheet of glass, plastic, or aluminum foil, which is coated with a thin layer of adsorbent material, usually silica gel, aluminum oxide (alumina), or cellulose. This layer of adsorbent is known as the stationary phase. After the sample has been applied on the plate, a solvent or solvent mixture (known as the mobile phase) is drawn up the plate via capillary action. Because different analytes ascend the TLC plate at different rates, separation is achieved. To quantify the results, the distance being considered is divided by the total distance travelled by the mobile phase. (The mobile phase must not be allowed to reach the end of the stationary phase).

$\mathrm{R}_{\mathrm{F}}=$ Distance travelled by the solute / Distance travelled by the solvent The plates are then removed, dried and seen under UV light chamber to view the separated bands clearly.

\section{Green synthesis of silver nanoparticles}

Aqueous extract of leaves, flower and fruits were prepared by dissolving of $5 \mathrm{~g}$ of respective sample powders in $50 \mathrm{ml}$ of distilled water and kept in water bath at $100^{\circ} \mathrm{C}$ for 15 mins. The filtrate obtained is then added to $1 \mathrm{~mm}$ of $\mathrm{AgNO}_{3}$ in the ratio 1:4 individually. The obtained sample solutions are then placed in water bath at $70^{\circ} \mathrm{C}$ for $15 \mathrm{mins}$ and incubated for overnight in a dark place. The presence of dark brown color indicates the presence of silver nitrate. The solutions are then centrifuged, and the obtained pellet is lyophilized and kept for further uses. ${ }^{9}$

\section{Characterization of silver nanoparticles}

The formation of AgNPs was followed by visual observation of color change from pale white to brown and was further confirmed by the sharp peaks given by the AgNPs in the visible region from UV - Vis spectrum of the reacting solution using Perkin-Elmer Lamda- 45 spectrophotometer, in a $1 \mathrm{~cm}$ path quartz cell at a resolution of $1 \mathrm{~nm}$ from 250 to $800 \mathrm{~nm}$. The studies on morphology, size, composition and the distribution of nanoparticles were performed by Transmission Electron Microscopic (TEM) analysis using a TEM, JEM- 1200EX, JEOL Ltd., Japan, Scanning Electron Microscope (SEM) using Hitachi S-4500 SEM and energy dispersive spectroscopy (EDAX) as an attachment on SEM. The probable biomolecules involved in the synthesis and stabilization of nanoparticles was recorded by FTIR spectrum using FTIR Nicolet Avatar 660 (Nicolet, USA). 


\section{RESULTS AND DISCUSSION}

The quest for new therapeutic agents is a continuous process and the role of natural compounds especially plant based products has gained immense attention as they remain a source of a wide range of chemical compounds that can be used for various medical purposes. In this scenario, the present investigation was carried out to explore the potential of the medicinal plant Couroupita guianensis. The study was started by initially identifying the physical characteristics of the extracts in the powder form followed by analysis of the extracts obtained using different solvents.

\section{POWDER CHARACTERISTICS}

The present investigation has described the characteristics of the plant powder and the extracts and is given in Table 1.

It is found that the fruit has the foul odor as reported in. ${ }^{10}$ It may due to the presence of sulphur compounds in the fruit. ${ }^{11}$ Extraction procedure plays a crucial role in the analysis of bioactive compounds both qualitatively and quantitatively.12 Various solvents were used in the present work for various parts of the plant namely leaves, flowers and fruits of Couroupita guianensis. It reveals that the ethyl acetate and chloroform extract of fruit have shown reddish violet and brownish purple color respectively. This may be due to the presence of indurubin (reddish pink pigment) in the fruit. ${ }^{13}$

\section{Phytochemical analysis of Couroupita guianensis}

A comparison of phytochemicals of different plant parts in different solvents was carried out and the results were provided in Table 2. Most of the phytochemicals were found to be observed in ethyl acetate and ethanol extracts than the water extracts in all the three plant parts. Carbohydrates, alkaloids, proteins, glycosides, Phytosterols, Flavonoids, tannins, Theobromine and terpenoids were found to be present in all the extracts except for saponins which is supported by the studies. ${ }^{14}$ Proteins and terpenoids were found to be absent in all water extracts. Flavonoids are the most important plant pigments for coloration ${ }^{15}$ and it is found to be highly present in fruit extracts which lead us to the conclusion that this may be responsible for the color of the extracts.

The obtained results show that the distribution of bioactive compounds not only varies from plant to plant but also varies within the parts of a plant. Phytochemical compounds present in the plants may not be necessarily required for normal functioning of the plant, but have a beneficiary effect on health or play an active role in amelioration of disease.

\section{Free radical scavenging activity of Couroupita guianensis extracts}

Antioxidants acts as a defense mechanism that protects against oxidative damage and include compounds to remove or repair damaged molecules. ${ }^{16}$ Oxidative stress is a factor for many human diseases as either a cause or an effect. Plants are the source of medication for preventive, curative, protective or promotive purposes. ${ }^{7}$ Imbalance leads to damage of important biomolecules and organs with potential impact on the whole organism.

Antioxidants can delay, inhibit or prevent the oxidation of oxidizable materials by scavenging free radicals and diminishing oxidative stress (Philip, 2004). Natural antioxidants have been studied extensively for decades to find compounds protecting against many diseases related to oxidative stress and free radical-induced damage.

To date, many plants have been claimed to pose beneficial health effects such as antioxidant properties. ${ }^{17}$ So the present investigation was started with an aim to evaluate the free radical scavenging activity of various extracts of Couroupita guianensis. The efficiency of the antioxidants in the extracts was determined by the $\mathrm{IC}_{50}$ values, denoting the concentration of the sample required to scavenge $50 \%$ of the DPPH free radicals and the results are provided in Table 3.

The results clearly indicate that though the leaf, flower and fruit extracts showed scavenging activity, the effect was less than the standard. $50 \%$ inhibition was obtained by the standard at $200(\mu \mathrm{g} / \mathrm{ml})$ but the same effect was brought about by higher concentration of flower and leaf extracts. Of the three extracts flower extracts showed comparatively higher activity than the others suggesting the presence of more amounts of antioxidant compounds in flower. The activity of ethyl acetate and chloroform extracts was more than the water extracts from all plant parts which supports our initial screening where the water extract showed the presence of minimal phytochemicals thereby showing negligible antioxidant activity. On the other hand, fruit chloroform extract showed more inhibition (67.85\%) than others and is on par with the standard there by making it the most effective part of the plant in terms of antioxidant activity. The presence of polyphenols in the fruit which are responsible for antioxidant activity would have made it more effective than the others as reported by ${ }^{18}$ earlier.

\section{Antibacterial activity of Couroupita guianensis extracts}

The antibacterial potential of the extracts was assessed against different bacteria by agar well diffusion method in comparison with standard antibiotic Streptomycin. The test organisms used were two gram negative bacteria (Pseudomonas aeuroginosa, Escherichia coli) and one gram positive bacteria (Bacillus subtilis). The results obtained were given in the Table 4.

The present investigation reveals that all the extracts except water extracts have shown significant antibacterial activity. From the results ( Figure 1), it was observed that zone of inhibition $(\mathrm{mm})$ against Pseudomonas aeuroginosa is found maximum in fruit chloroform extract $(14 \mathrm{~mm})$ which is more than the positive control $(10 \mathrm{~mm})$, leaf chloroform extract is found more effective $(10 \mathrm{~mm})$ against Escherichia coli) but less than its positive control $(11 \mathrm{~mm})$ and both leaf ETAC $(13 \mathrm{~mm})$ and chloroform $(13 \mathrm{~mm})$ extract has shown the maximum potential against Bacillus subtilis more than its positive control $(6 \mathrm{~mm}$ and $10 \mathrm{~mm}$ respectively).

Hence it is found that the chloroform extracts exhibit the high potential activity against both $g$ positive and $g$ negative bacteria. Since water extracts didn't answer so well in any of the above tests, future study is focused only on ethyl acetate and chloroform extracts

\section{Thin layer chromatography (TLC) analysis}

TLC analysis of ethyl acetate and chloroform extracts of leaves, flowers and fruits of Couroupita guianensis revealed the presence of active compounds that were visualized in UV. Different solvent systems were tried for each extract to obtain the clear bands (Trial and error method). The solvent systems used are tried in different combinations based on the polarity of the compound as reported. ${ }^{19}$ The solvent system used, their ratio, number of bands obtained, and their $R_{F}$ value is given in the following Table 5.

The standard solvent system tried was ethyl acetate (polar): hexane (non-polar) in the ratio 1:1 for which only the leaf ethyl acetate gives the positive result. The ratio is altered by increasing the hexane solvent for which the flower ethyl acetate gave the positive result, but only one band is formed. The other solvents used are methanol and chloroform which are polar and non-polar solvents respectively.

From the results, it is observed that the fruit ethyl acetate extract and flower and fruit chloroform extract have shown more than 4 bands. Pink and sky-blue color pigmentation was observed in the fruit extracts this may be due to presence of the pigments in the fruit. Leaf extracts runs very fast in the TLC plate when compared to the other extracts. 
Table 1: Physical characteristics of leaf, flower and fruit powder and extracts.

\begin{tabular}{cccc}
\hline & \multicolumn{2}{c}{ POWDER CHARACTERISTICS } & \\
\hline CHARACTERS & LEAF & FLOWER & FRUIT \\
Colour & Green & Light brown & Dark brown \\
Odour & Acceptable & Acceptable & Foul \\
Taste & Bitter & Bitter & Bitter \\
Texture & Smooth & Smooth & Rough \\
& EXTRACT CHARACTERISTICS & \\
SAMPLES & EXTRACTS & COLOUR & CONSISTENCY \\
& Ethyl acetate & Dark green & Sticky \\
Leaf & chloroform & Green & Semi solid \\
& Aqueous & Brownish green & Watery \\
& Ethyl acetate & Light brown & Watery \\
Flower & Chloroform & Brown & Semi solid \\
& Aqueous & Dark brown & Watery \\
& Ethyl acetate & Reddish violet & Resinous \\
& Chloroform & Brownish purple & Oily \\
& Aqueous & Sand & Watery \\
\hline
\end{tabular}

Table 2: Phytochemical analysis of the extracts.

\begin{tabular}{cccccccccccc}
\hline & \multicolumn{3}{c}{ Leaf extracts } & \multicolumn{3}{c}{ Flower extracts } & \multicolumn{3}{c}{ Fruit extracts } \\
\hline COMPONENTS & ETAC & $\mathrm{CHCL}_{3}$ & $\mathrm{H}_{2} \mathrm{O}$ & $\mathrm{ETAC}$ & $\mathrm{CHCL}_{3}$ & $\mathrm{H}_{2} \mathrm{O}$ & $\mathrm{ETAC}$ & $\mathrm{CHCL}_{3}$ & $\mathrm{H}_{2} \mathrm{O}$ \\
\hline Carbohydrates & ++ & + & ++ & ++ & ++ & + & ++ & ++ & + \\
Alkaloids & ++ & ++ & + & + & ++ & + & ++ & ++ & ++ \\
Proteins and A.A & ++ & ++ & - & + & ++ & - & ++ & ++ & - & + \\
Theobromine & + & + & + & ++ & + & + & + & + & + \\
Saponins & - & - & - & - & - & - & - & - & - & + \\
Glycosides & + & ++ & + & ++ & + & + & + & ++ & + \\
Phytosterols & ++ & + & + & + & + & - & ++ & + & + \\
Flavonoids & + & ++ & - & + & + & + & ++ & ++ & + \\
Tannins & + & + & + & + & ++ & + & + & ++ & + \\
Terpenoids & ++ & + & - & + & ++ & - & ++ & ++ & + \\
\hline
\end{tabular}

$\left(\right.$ ETAC $=$ Ethyl acetate, $\mathrm{CHCL}_{3}=$ Chloroform, $\mathrm{H}_{2} \mathrm{O}=$ Water $;++$ represents highly present, + represents moderately present and - represents absent $)$

Table 3: Antioxidant activity of Couroupita guianensis.

\begin{tabular}{|c|c|c|c|c|c|c|c|c|c|c|}
\hline \multirow{3}{*}{$\begin{array}{l}\text { Concentration } \\
\qquad(\mu \mathrm{g} / \mathrm{ml})\end{array}$} & \multicolumn{10}{|c|}{$\%$ Inhibition } \\
\hline & \multirow{2}{*}{ Ascorbic acid } & \multicolumn{3}{|c|}{ Flower Extract } & \multicolumn{3}{|c|}{ Leaf Extract } & \multicolumn{3}{|c|}{ Fruit Extract } \\
\hline & & ETAC & $\mathrm{CHCL}_{3}$ & $\mathrm{H}_{2} \mathrm{O}$ & ETAC & $\mathrm{CHCL}_{3}$ & $\mathrm{H}_{2} \mathrm{O}$ & ETAC & $\mathrm{CHCL}_{3}$ & $\mathrm{H}_{2} \mathrm{O}$ \\
\hline 50 & 11.9 & 13.09 & 2.38 & 1.19 & 3.5 & 2.38 & 1.19 & 14.28 & 9.523 & 1.19 \\
\hline 100 & 25 & 29.76 & 5.95 & 2.38 & 10.71 & 16.66 & 3.57 & 23.8 & 22.61 & 4.76 \\
\hline 150 & 33.33 & 30.95 & 21.42 & 4.76 & 17.85 & 26.19 & 8.33 & 29.76 & 38.09 & 8.33 \\
\hline 200 & 51.19 & 47.61 & 30.95 & 7.142 & 30.95 & 29.76 & 11.9 & 38.09 & 42.85 & 10.71 \\
\hline 250 & 72.6 & 54.76 & 41.66 & 10.71 & 50 & 44.08 & 15.48 & 45.23 & 61.9 & 13.09 \\
\hline 300 & 75 & 59.52 & 50 & 14.285 & 55.9 & 51.19 & 16.67 & 53.57 & 67.85 & 19.04 \\
\hline
\end{tabular}

The flower extracts were light in color hence it is difficult to interpret the sample run when placed inside the solvent system. Leaf b) Flower c) Fruit

RF obtained denotes the polarity of the separated bands, larger the RF values lower the polarity of the compounds and vice versa. That is the RF value obtained is inversely proportional to the polarity of the compound. From the results obtained, it may be interpreted that these extracts have many different bioactive compounds which can be further analyzed by GC-MS in future work. The picture representation was shown in the Figure 2. 
Prakash, et al:: Analysis of biochemical compounds of leaf, flower and fruit of couroupita guianensis and synthesis of silver nanopraticles.

\section{Table 4: Antibacterial activity of various extracts of Couroupita guianensis.}

\begin{tabular}{|c|c|c|c|c|c|c|c|c|c|c|c|c|}
\hline \multirow{3}{*}{ Test organism } & \multicolumn{12}{|c|}{ Zone of inhibition (mm) } \\
\hline & \multirow{2}{*}{$\begin{array}{l}\text { Positive } \\
\text { control }\end{array}$} & \multicolumn{3}{|c|}{ Flower Extract } & \multirow{2}{*}{$\begin{array}{l}\text { Positive } \\
\text { control }\end{array}$} & \multicolumn{3}{|c|}{ Leaf Extract } & \multirow{2}{*}{$\begin{array}{l}\text { Positive } \\
\text { control }\end{array}$} & \multicolumn{3}{|c|}{ Fruit Extract } \\
\hline & & ETAC & $\mathrm{CHCL}_{3}$ & $\mathrm{H}_{2} \mathrm{O}$ & & ETAC & $\mathrm{CHCL}_{3}$ & $\mathrm{H}_{2} \mathrm{O}$ & & ETAC & $\mathrm{CHCL}_{3}$ & $\mathrm{H}_{2} \mathrm{O}$ \\
\hline $\begin{array}{c}\text { Escherichia } \\
\text { coli }\end{array}$ & 12 & 3 & 3 & 3 & 11 & 8 & 10 & nil & 1 & 9 & 8 & nil \\
\hline
\end{tabular}

Table: 5 Thin Layer Chromatography results.

\begin{tabular}{cccc}
\hline EtOH Extracts & Leaf & Flower & Fruit \\
\hline Mobile Phase & HEX:ETAC $(1: 1)$ & HEX:ETAC $(3: 2)$ & HEX:ETAC:MeOH $(3: 1: 1)$ \\
RF Value & $0.61,0.761$ and 0.833 & 0.828 & $0.212,0.297,0.489,0.595,0.744$, and 0.914 \\
CHCL $_{3}$ Extracts & HEX:ETAC:MeOH $(3: 1: 1)$ & HEX:ETAC:MeOH:CHCL & HEX:ETAC:MeOH $(2: 1: 2)$ \\
RF Value & $0.425,0.475,0.725,0.800,0.825$ & $0.485,0.585,0.658,0.756,0.804$ & $0.660,0.720,0.760$ \\
\hline
\end{tabular}

Table: 6 Antibacterial activity of synthesized silver nanoparticles.

\begin{tabular}{|c|c|c|c|}
\hline \multirow[b]{2}{*}{ SAMPLES } & \multicolumn{3}{|c|}{ Zone of inhibition (mm) } \\
\hline & $\begin{array}{l}\text { Pseudomonas } \\
\text { aeuroginosa }\end{array}$ & Bacillus subtilis & Escherichia coli \\
\hline Streptomycin & 9 & 6 & 10 \\
\hline Leaf - nanoparticles & 6 & 6 & 5 \\
\hline Flower-nanoparticles & 14 & 15 & 13 \\
\hline Fruit - nanoparticles & 5 & 2 & 3 \\
\hline
\end{tabular}
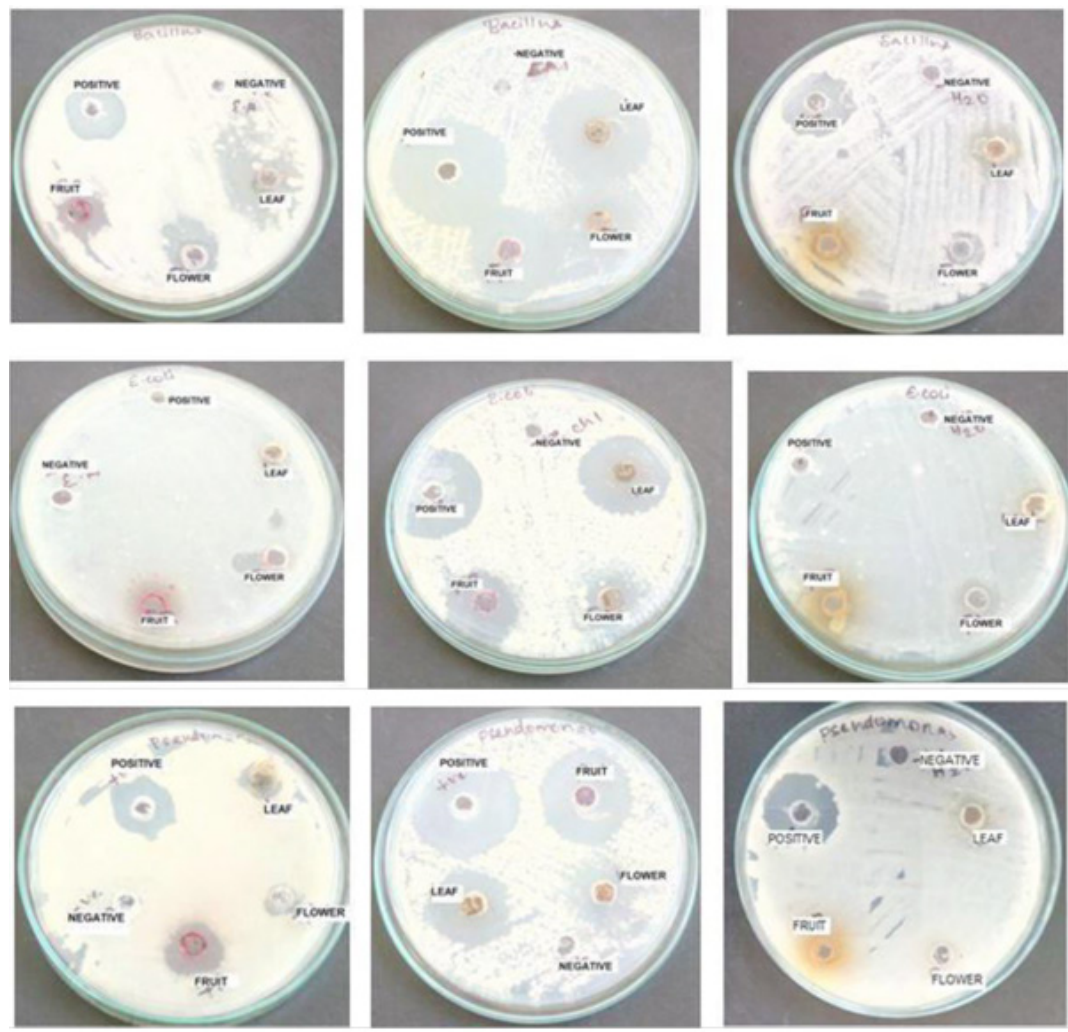

Figure 1: Antibacterial activity of plant extracts. 

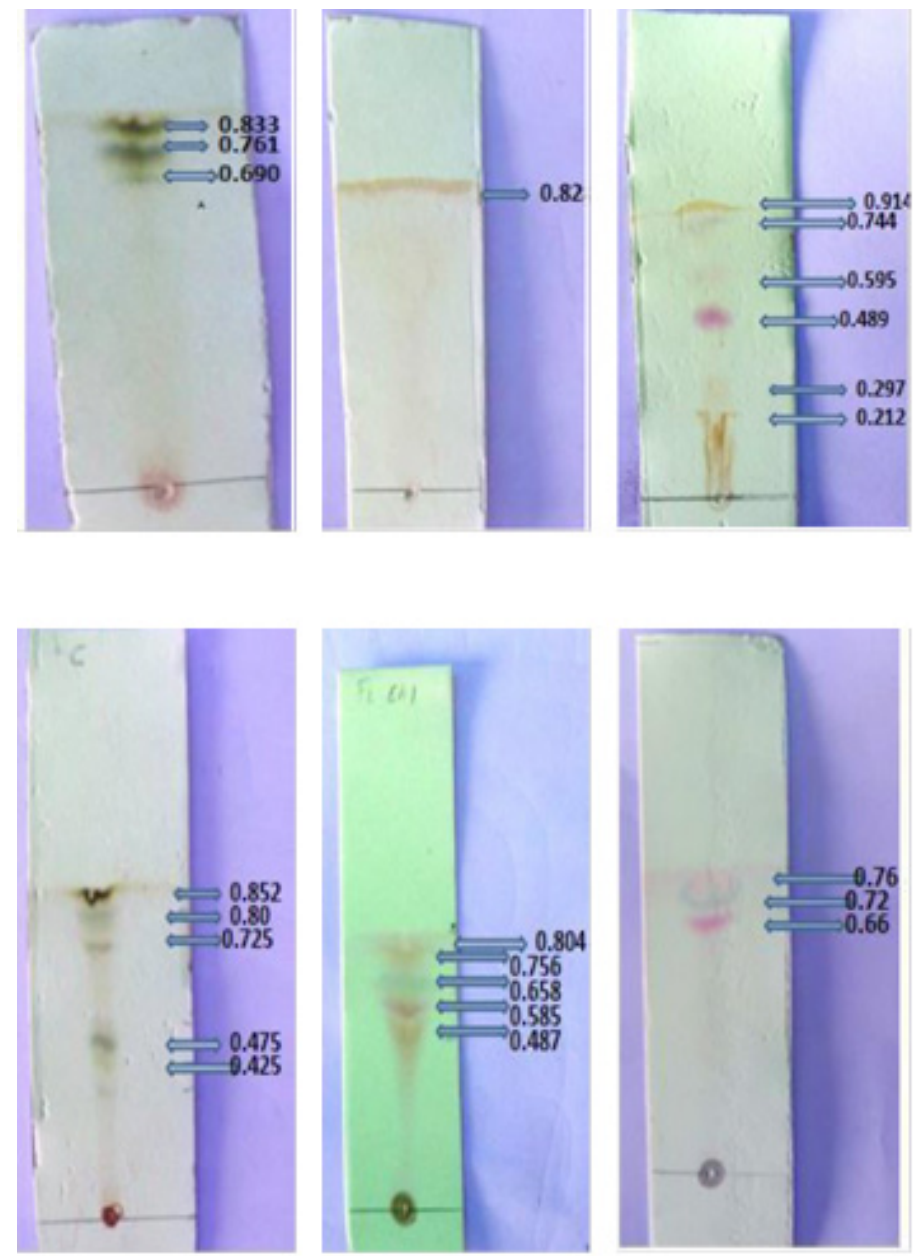

Figure 2: TLC analysis of the extracts A) Ethyal acetate Extract: a) Leaf b) Flower c)Fruit B) Chloroform Extracts: a) Leaf b) Flower c)Fruit.

\section{Synthesis of silver nanoparticles}

The ability of the extracts of Couroupita guianensis to reduce metals to nano sizes was checked by aqueous extracts of leaves, flowers and fruits of Couroupita guianensis using $1 \mathrm{mM}$ of AgNO3. The formation of silver nanoparticles was initially observed by the change in colour from pale white to brown. This change was very clearly noticed with the flower extract unlike the leaf and fruit extract that didn't show notable colour change.

\section{UV-Visible spectroscopy}

The characteristic brown color arises due to excitation of surface plasmon vibrations in the silver metal nanoparticles. ${ }^{20,21}$ This bioreduction of Silver nitrate ions was followed by UV-vis spectroscopy (Figure 3). The leaf, flower and fruit synthesized nanoparticles showed absorbance peak at $416 \mathrm{~nm}, 434 \mathrm{~nm}$ and $416 \mathrm{~nm}$ respectively indicating the presence of spherical or roughly spherical AgNPs that remained the same throughout the reaction period, suggesting that the particles are dispersed in the aqueous solution with no evidence for aggregation..$^{22}$

\section{Antibacterial activity of silver nanoparticles}

The antibacterial potential of FSNPs was evaluated by agar well diffusion method using Streptomycin as standard. The test organisms used were two g negative bacteria (Pseudomonas aeuroginosa, Escherichia coli) and one g positive bacteria (Bacillus subtilis). The results are given in the Table 6 and Figure 4.

From the results obtained, the FSNPs show maximum zone of inhibition against all the test organisms than the standard. It may be because of the phytochemical constituents present in the flower that helps in the reduction of silver nanoparticles and these nanoparticles may diffuse through the medium more effectively than the others. Since flower synthesized nanoparticles (FSNPs) showed more efficient results, these FSNPs were characterized using instrumental analyses.
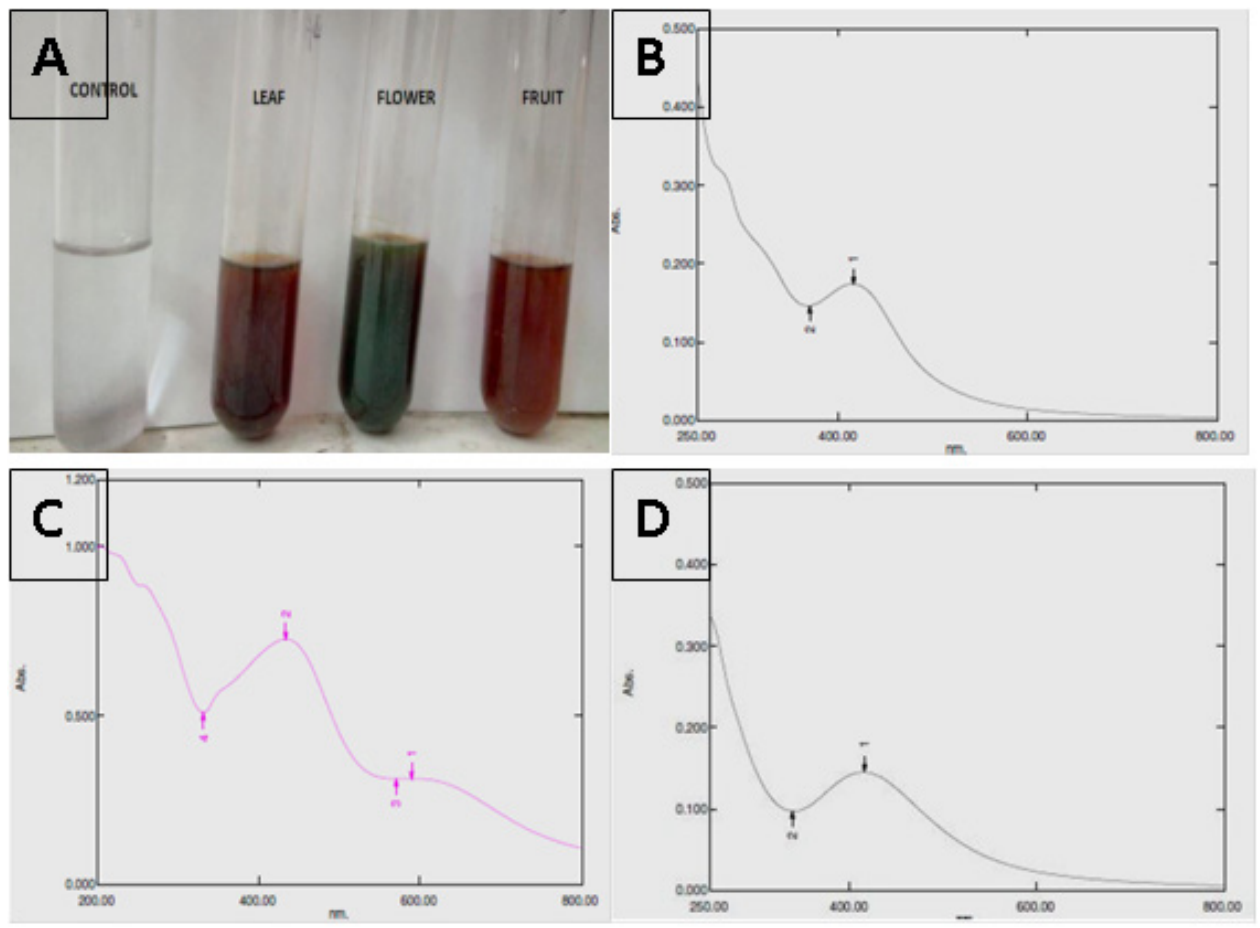

Figure 3: Color Change of Silver nanoparticles; UV-Vis spectrum of Silver nanoparticles B) Leaf C) Flower C) Fruit. 


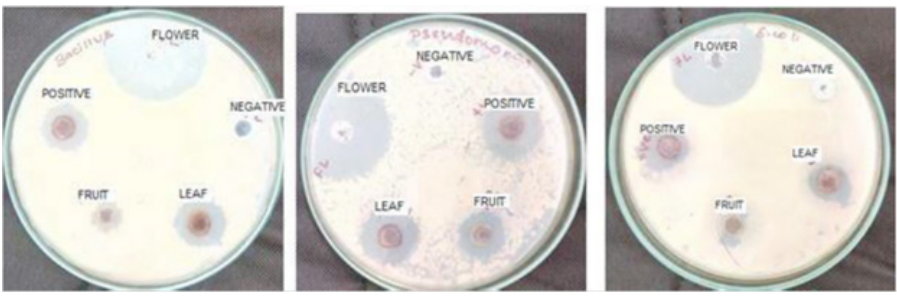

Figure 4: Antibacterial activity of silver nanoparticles.
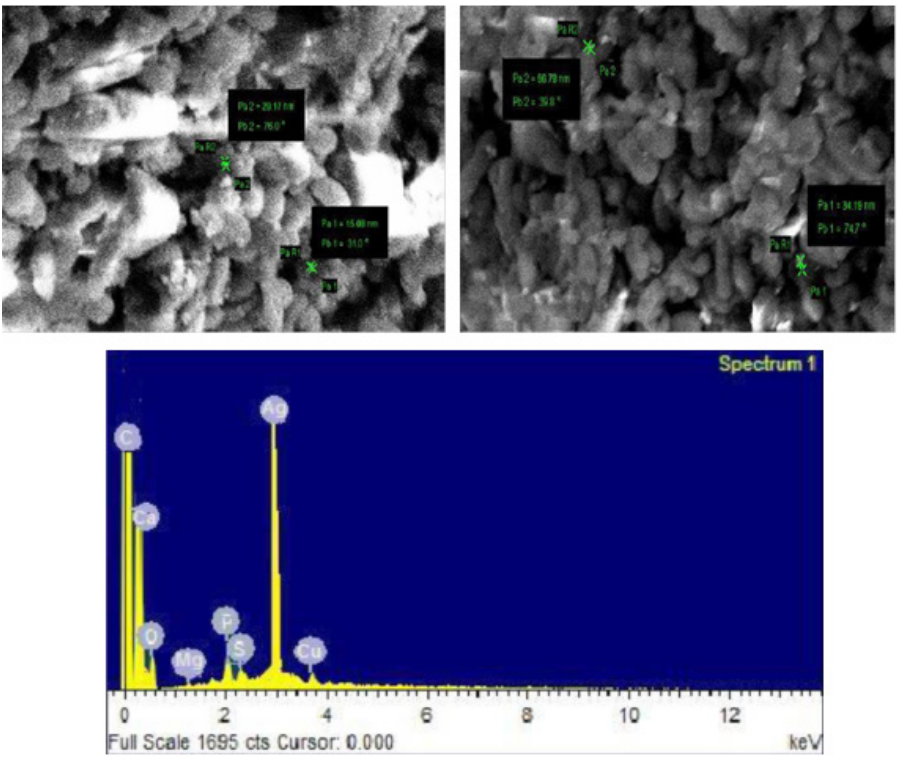

Figure 5: SEM micrograph and EDX analysis of flower synthesized Silver nanoparticles.

\section{Characterization of silver nanoparticles}

The formation of silver nanoparticles was confirmed by color change and UV-Vis spectrum. The morphology and size of the nanoparticles and their elemental composition was determined by SEM-EDAX analysis. SEM is routinely used to generate high-resolution images of shapes of objects and to show spatial variations in chemical compositions. In the present work, SEM technique was employed to visualize the size and shape of silver nanoparticles (Figure 5).

The shape of the nanoparticles was spherical with the size in the range of $15-57 \mathrm{~nm}$ and were found to be clustered. Similar shape of silver nanoparticles is reported. ${ }^{23}$ The silver nanoparticles formed are not mono disperse in nature. The larger silver particles may be due to the aggregation of the smaller ones. ${ }^{24}$ The difference in size may be due to the availability of different quantity and nature of capping agents present in the flower extract. This is also supported by the shifts and difference in areas of the peaks obtained in the FTIR analysis.

EDX analysis is used to give the qualitative as well as quantitative status of elements in the sample. Figure shows elemental profile of synthesized nanoparticles using cannonball flower extracts. The EDX spectrum reveals strong signal in the silver region and confirms the presence of silver. Metallic silver nano crystals generally show typical optical absorption peak approximately at $3 \mathrm{KeV}$ due to Surface Plasmon resonance. ${ }^{25}$ The elemental analysis of the silver nanoparticles shown in the Figure revealed highest proportion of silver followed by $\mathrm{C}$, and $\mathrm{Ca}$. Other peak corresponding to $\mathrm{Cu}$ in the EDX is an artifact of the $\mathrm{Cu}$-grid on which the sample was coated. ${ }^{26}$ There were no other peaks and this confirms the complete reduction of silver compounds to silver nanoparticles as shown in the spectrum.

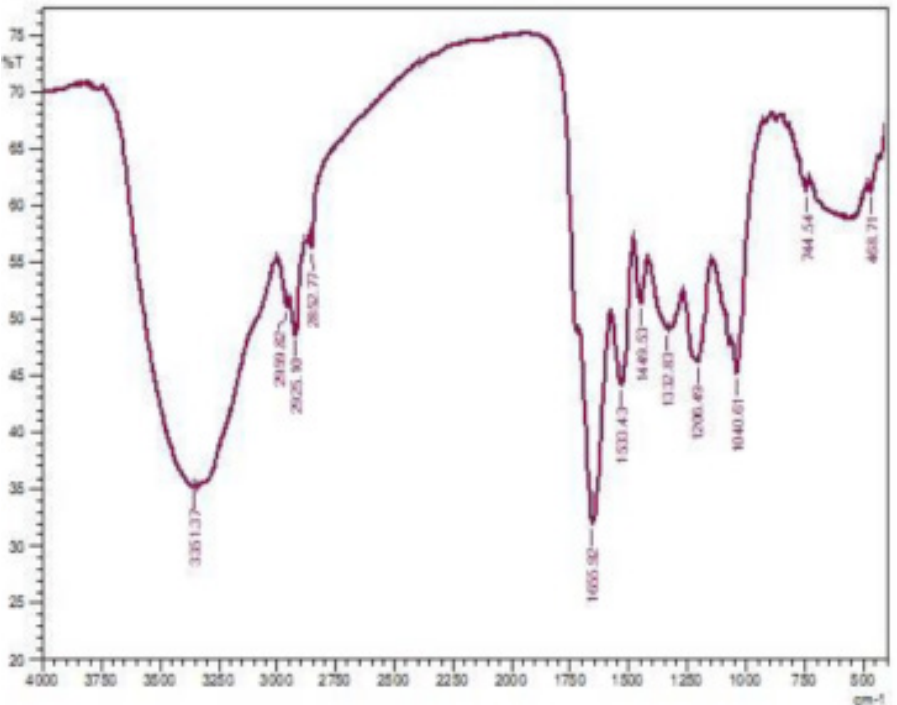

Figure 6: FTIR spectra of silver nanoparticles.

FTIR spectral analysis of the silver nanoparticles was carried out to identify the nature of compounds present in the sample. FTIR spectra provides information about the local molecular environment of the organic molecules on the surface of nanoparticles. In the present work, FTIR spectral measurements were carried out to identify the potential biomolecules in cannonball flower extract that may be responsible for reducing and capping the bio reduced silver nanoparticles. ${ }^{27}$ The observed intense bands were compared with standard values to identify the functional groups. The FTIR spectra of pure flower extract (FE) and flower synthesized nanoparticles (FSNPs) sample were compared and it showed considerable variation in the peaks of spectra (Figure 6).

Seventeen peaks were found in the flower sample where as in the purified silver nanoparticles only 12 peaks were found. The reduction of certain peaks is the clear indication of the loss of certain groups. The band at 3398.63 and $3351.37 \mathrm{~cm}^{-1}$ in the FE and FSNPs spectra corresponds to $\mathrm{O}-\mathrm{H}$ stretching vibration indicating the presence of alcohol and phenol. A peak at 1726.32 (ester group) is found only in the spectrum of FE and not found in the FSNPs (Figure 8). The wave number from $1200-800 \mathrm{~cm}^{-1}$ has 5 stretches in $\mathrm{FE}$ which is responsible for $\mathrm{N}-\mathrm{H}$ stretch vibration present in the amide linkages of the proteins. These functional groups have role in stability/capping of silver nanoparticles as reported in many studies ${ }^{28,29}$ but only one stretch is found in nanoparticles. Hence from the results obtained it may be concluded that these changes in the functional groups may be responsible for the formation of bio reduced silver nanoparticles.

\section{CONCLUSION}

The aim of the present investigation is to compare the various extracts of leaves, flower and fruits of Couroupita guianensis which showed variation in the physical characteristics. The presence of phytochemicals was noticed predominantly in ethyl acetate and chloroform extracts compared to the water extract. When checked for bioactivities, the ethyl acetate and chloroform extracts only showed effective antioxidant and antibacterial activity compared to water extracts indicating the presence of phytochemicals in these compounds which was further confirmed by TLC analysis that showed many bands in flower and fruit extracts. These extracts were also tested for their ability to synthesize silver nanoparticles. Flower extracts showed the formation of silver nanoparticles better than the other parts and also these showed good antimicrobial activity against 
Prakash, et al:: Analysis of biochemical compounds of leaf, flower and fruit of couroupita guianensis and synthesis of silver nanopraticles.

the test organisms. These nanoparticles were found to be spherical with size in the range of $15-57 \mathrm{~nm}$. This study therefore proves the variation in the different parts of the plant in terms of phytochemicals as well as bioactivities and hence suggests the efficient use of these plant parts appropriately for medical and industrial uses.

\section{ACKNOWLEDGEMENT}

The authors would like to thank Sathyabama University for the support in carrying out the research.

\section{CONFLICT OF INTEREST}

The authors declare that there is no conflict of interest.

\section{ABBREVIATIONS USED}

Cm: Centimeter; Mm: Millimeter; Nm: Nanometer; ETAC: Ethyl acetate; $\mathbf{C H C L}_{3}$ : Chloroform; IC $_{50}$ : Inhibitory concentration of $50 \%$; HEX: Hexane; MeOH: Methanol; RF: Retention factor; $\mathbf{A g N O}_{3}$ : Silver nitrate; UV-Vis: Ultra Violet-Visible Spectroscopy; FTIR: Fourier Transform Infrared Spectroscopy; SEM: Scanning Electron Microscopy; EDX: Energy-Dispersive X-ray spectroscopy; DPPH: 1, 1-diphenyl-2-picrylhydrazyl; TLC: Thin Layer Chromatography.

\section{REFERENCES}

1. Abdul Wadood, MehreenGhufran, Jamal SB, Naeem M, Ajmal Khan, Rukhsana Ghaffar and Asnad. Phytochemical analysis of medicinal plants occurring in local area of mardan. Biochem Anal Biochem. 2013;2(4):1-4

2. Asadujjaman, Aslam-Hossain, Karmakar UK. Assessment of DPPH free radica scavenging activity of some medicinal plants. Journal of medicinal plant studies. 2013(1): 1161-5.

3. Udapudi B, Naik PK, Savadatti ST, Rupali Sharma, Samprita Balgi. Synthesis and characterization of silver nanoparticles. International Journal of Pharmacy and Biological Sciences. 2003;2(3):10-4.

4. Gousia SK, Kumar AK, Kumar TV, Latha NL. Biological activities and medicinal properties of Couroupita guianensis. International Journal of Pharmacy and Pharmaceutical Science Research. 2013;3(4):140-3.

5. Gupta SK, Ghoshal M, Choudary D, Mandal P. Assessment of Antioxidant activity and polyphenolic content of Couroupita guianensis during flower and fruit maturation. International Journal of Recent Scientific Research 5(5):940-7.

6. Karthika R, Sevarkodiyone SP. Synthesis and characterization of silver nanoparticles using aqueous extract goat faecal pellets. International journal of current science research. 2015;1(1):1-7.

7. Kaviya S, Santhanalakshmi J, Viswanathan B, Muthumar J, Srinivasan. Biosynthesis of silver nanoparticles using citrus sinensis peel extract and its antibacteria activity. Spectrochimica Acta Part A: Molecular and Biomolecular Spectroscopy. 2011;79(3):594-8.

8. Manimegalai S, Sridharan TB, Pathy MR, Rajeshwari V. Antioxidant, phytochemical screening and antimicrobial activity of Couroupita guianensis flower extract. Der Pharmacia Lettre. 2014;6(6):251-6.

9. Minaeian S, Shahverdi AR, Nohi AS, Shahverdi HR. Extracellular biosynthesis of silver nanoparticles by some bacteria. J. Sci. I. A. U (JSIAU). 2008;17(66):1-4

10. Mohammed A, Bhawani SA, Sharma S. Analysis of Herbal products by Thin Layer Chromatography: A review. International Journal of Pharma and Bio Sciences. 2010: 1(2):1-50.
11. Nelson EK, Wheeler DH. Some constituents of the cannonball fruits. J. Am. Chem. Soc. 1937:59(12):2499-2500

12. Niraimathi $K L$, Sudha $V$, Lavanya $R$, Brindha P. Biosynthesis of silver nanoparticles using Alternanthera sessilis (Linn.) extract and their antimicrobial, antioxidant activities Colloids and Surfaces B: Biointerfaces. 2013;102:288-91.

13. Philip Molyneux, Songklanakarin J. The use of the stable free radical Diphenyl Picryl Hydrazyl (DPPH) for estimating antioxidant activity. Songklanakarin J. Sci. Technol. 2004;26(2):211-9.

14. Prakash P, Gnanaprakasam P, Emmanuel R, Arokiyaraj S, Saravanan M. Green synthesis of silver nanoparticles from leaf extract of Mimusops elengi, Linn. for enhanced antibacterial activity against multi drug resistant clinical isolates. Colloids and Surfaces B: Biointerfaces. 2013;108:255-9.

15. Tiwari P, Kumar B, Kaur M, Kaur G, Kaur H. Phytochemical screening and extraction: a review. International Pharmaceutica sciencia. 2011;1(1):98-106.

16. Deavaraj $P$, kumara $P$, Aarti $C$, Renganathan A. Synthesis and characterization of silver nanoparticles using cannonball leaves and their cytotoxic activity against MCF-7 cell line. Journal of Nanotechnology. 2013;3:1-5

17. Priti B, Ravindra TV, Adivarekar. Extraction of indigo dye from Couroupita guianensis and its application of cotton fabric. Fashion and Textiles. 2014;1(1):16.

18. Raveendra B, Kiran S, Kumari V, Jyothi R, Bhavani D. "UV Spectrophotometric Method for the Estimation of Roflumilast in Human Serum. Pharm Anal Acta. $7(6): 1-4$.

19. Singh R, Kumari N, Gangwar M, Nath G. Qualitative characterization of phytochemical and in vitro antimicrobial evaluation of leaf extract of Couroupita guianensis Aubl - a threatened medicinal tree. Int J Pharm Pharm Sci. $2015 ; 7(7): 212-5$

20. Sadowski Z, Maliszewska IH, Grochowalska I, Polowczyk T, Ozlecki. Synthesis of silver nanoparticles using microorganisms. Materials Science-Poland. 2008; 26(2):419-24.

21. Banu SK, Catherine L. General techniques involved in phytochemical analysis. International Journal of Advanced Research in Chemical Science. 2015;2(4):25-32

22. Saifuddin N, Wong CW, Nuryasumira AA. Rapid Biosynthesis of Silver Nanoparticles Using Culture Supernatant of Bacteria with Microwave Irradiation. E-J Chem, 2009;6(1):61-70.

23. Sasidharan S, Chen Y, Saravanan D, Sundram KM, Latha YL. Extraction, isolation and characterization of bioactive compounds from plants' extracts. African Journal of Traditional Complementary and Alternative Medicines. 2011;8(1):1-10.

24. Satyavati GV, Raina MK, Sharma M. Medicinal Plants of India", Indian Council of Medical Research. Cambridge printing works: New Delhi. 1976;4.

25. Tailor Chandra Shekar and Goyal Anju. Antioxidant activity by DPPH radical scavenging method of ageratum conyzoids linn. Leaves.American Journal of Ethnomedicine. 2014;1(4):244-9

26. Yamamoto Y, Gaynor RB. Therapeutic potential of inhibition of the NF-kappaB pathway in the treatment of inflammation and cancer. J Clin Invest. 2001; 107(2):135-42

27. Yusuf, Zakir A, Shemau, Abdullahi A, Haalima SA. Phytochemical analysis of the methanol leaves extract of Paullinia pinnata linn. Journal of Pharmacognosy and Phytotherapy. 2014;6(2):10-16.

\section{SUMMARY}

- This study tries to compare the antibacterial potential of various extracts of different parts of Couroupita guianensis. Additionally, this study demonstrates the ability of this plant in synthesizing silver nanoparticles in which it was noticed that flower extract was successful in synthesizing silver nanoparticles (size $15-57 \mathrm{~nm}$ ) efficiently compared to that of leaf and fruit extracts which also showed significant antibacterial activity. Therefore this study advocates the potential of this plant in producing various bioactive compounds. 
GRAPHICAL ABSTRACT
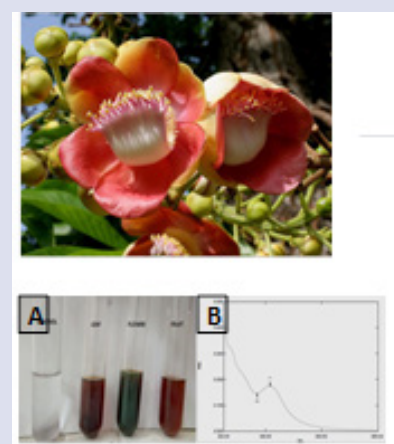

C $\quad$ D
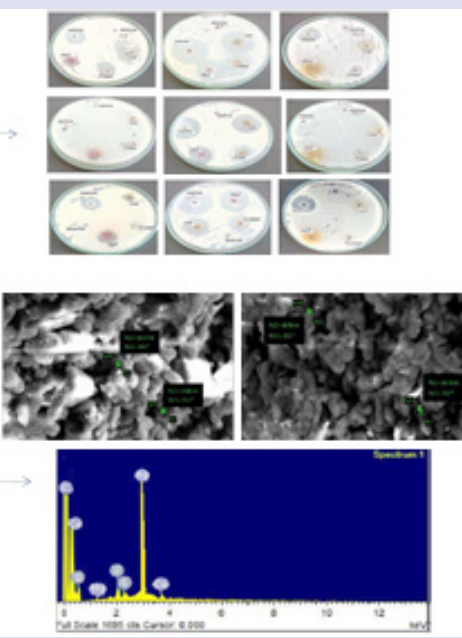

\section{ABOUT AUTHORS}

The authors have been working in the field of Humic acid research, microbial biotechnology, environmental biotechnology and nanotechnology for the past 5 years and have published papers in Web of science and scopus indexed journals.

Cite this article: Pandurangan P, Sahadeven M, Sunkar S, Dhana SKNM. Comparative Analysis of Biochemical Compounds of Leaf, Flower and Fruit of Couroupita guianensis and Synthesis of Silver Nanoparticles. Pharmacog J. 2018;10(2):315-23. 